\title{
Lung transplantation for pulmonary hypertension
}

\author{
Ann Hwalek ${ }^{1}$, Justin P. Rosenheck ${ }^{2}$, Bryan A. Whitson ${ }^{1}$ \\ ${ }^{1}$ Division of Cardiac Surgery, Columbus, Department of Surgery, The Ohio State University Wexner Medical Center, OH, USA; ${ }^{2}$ Division of \\ Pulmonary, Critical Care \& Sleep Medicine, The Ohio State University Wexner Medical Center, Columbus, OH, USA \\ Contributions: (I) Conception and design: All authors; (II) Administrative support: None; (III) Provision of study materials or patients: None; (IV) \\ Collection and assembly of data: None; (V) Data analysis and interpretation: None; (VI) Manuscript writing: All authors; (VII) Final approval of \\ manuscript: All authors. \\ Correspondence to: Bryan A. Whitson, MD, PhD, FACS. Professor of Surgery, The Jewel and Frank Benson Family Research Professor, Director, \\ Section of Thoracic Transplantation and Mechanical Circulatory Support, Co-Director, COPPER Laboratory, Department of Surgery, Division of \\ Cardiac Surgery, N-816 Doan Hall, 410 W. 10th Ave., Columbus, OH 43210, USA. Email: bryan.whitson@osumc.edu.
}

\begin{abstract}
From its identification as a distinct disease entity, understanding and management of pulmonary hypertension has continuously evolved. Diagnostic and therapeutic interventions have greatly improved the prognostic implications of this devastating disease, previously rapidly and uniformly fatal to one chronically managed by multi-disciplinary teams. Improved diagnostic algorithms and active research into biochemical signatures of pulmonary hypertension $(\mathrm{PH})$ have led to earlier diagnosis of $\mathrm{PH}$. Medical therapy has moved from upfront use of continuous intravenous prostaglandins to administration of combinations of oral medications targeting multiple pathways underlying this disease process. In addition to improved medical therapies, recently introduced interventions such as pulmonary endarterectomy and pulmonary artery balloon angioplasty for chronic thromboembolic pulmonary hypertension (CTEPH) give patients an increasing array of treatment options. Despite these many advances, lung transplantation remains the definitive treatment for patients with disease refractory to or progressing on best medical therapy. As our understanding of medical therapy has advanced, so to have best practices for lung transplantation. Recipient selection and approach to organ transplantation techniques have continuously evolved. Mechanical circulatory support has become increasingly employed to bridge patients through lung transplantation in the immediate post transplantation recovery. In this review, we give a history of lung transplantation for $\mathrm{PH}$, an overview of $\mathrm{PH}$, discuss current best practices and look to the future for insights into the care of these patients.
\end{abstract}

Keywords: Pulmonary hypertension (PH); lung transplantation; pulmonary artery hypertension

Submitted Dec 29, 2020. Accepted for publication May 14, 2021.

doi: $10.21037 /$ jtd-2021-20

View this article at: https://dx.doi.org/10.21037/jtd-2021-20

\section{Introduction and background}

Pulmonary hypertension ( $\mathrm{PH})$ is a complex and heterogeneous set of disease processes that significantly affect patients' lives. Though the true incidence is unknown, ranges vary from 2-15 individuals per million population. Part of the reason for this wide range is the heterogeneity of the disease processes that comprise $\mathrm{PH}$, variations in management and the clinical expression of the $\mathrm{PH}$ disease process, which can be a confounder to other pathophysiology.
To facilitate a standard nomenclature, and potentially diagnosis and management of patients with $\mathrm{PH}$, the World Health Organization has grouped $\mathrm{PH}$ in to the following five categories:

(I) Pulmonary artery hypertension (PAH) —an intrinsic pulmonary vascular process;

(II) $\mathrm{PH}$ secondary to left heart disease-including myocardial dysfunction and valvular diseases;

(III) $\mathrm{PH}$ secondary to lung disease and/or hypoxiaa secondary process such as that from pulmonary fibrosis or sleep disordered breathing; 
(IV) $\mathrm{PH}$ secondary to pulmonary arterial obstructionsincluding chronic thromboembolic pulmonary hypertension (CTEPH);

(V) $\mathrm{PH}$ secondary to unclear and/or multifactorial mechanisms-including blood dyscrasis and sarcoidosis.

Over the past 20 years, the medical management of group 1, true PAH, has evolved. A management strategy for patients with refractory PAH is (bilateral) lung transplantation. The contribution of lung transplantation to the management of PAH (group 1) is the focus of this review.

\section{Historical perspective}

The term "primary pulmonary hypertension" has been well described in the literature since 1951 (1). Simultaneous to the evolving understanding of this newly minted disease, techniques for and management of lung transplantation were being refined throughout the 1960s and 1970s. In 1968 , a major milestone was achieved for patient survival after lung transplant when a patient survived 10 months following a single lung transplant (2). As work with immunosuppressive regimens advanced-including the clinical use of the calcineurin inhibitor cyclosporinesurgeons at Stanford translated the laboratory work of Doctors Shumway, Wallwork, and Reitz into clinical practice by performing the first heart-lung transplant in 1981 for a 45 -year-old female patient with end stage primary PH (3). Since the 1980s, almost 20 years after the first lung transplant in 1963 by Hardy and associates, lung transplant has been an accepted treatment for PH (4).

Due to scarcity of organ blocks for heart-lung transplants, the transplant community has transitioned towards lung transplantation alone for those suffering from PH. This is evident in the 2019 International Thoracic Organ Transplant Registry that reported data from 69,200 adult lung and 4,128 adult heart-lung transplants through June 2018 (5). In part, this transition was due to the recognition that the primary pathophysiology in this disease is within the pulmonary vasculature and is not due to intrinsic right ventricular issues. Indeed, the right ventricle demonstrates a remarkable ability to recover to a physiologic state over time after the removal of the high resistance pulmonary vasculature (6).

In specific patient populations like $\mathrm{PH}$, bilateral lung transplant (BLT) has found increasing popularity. A review article in Annals of Surgery in 1993 noted two key reasons for BLT preference, including minimizing early postoperative issues with $\mathrm{PH}$ crisis and an improved tolerance of bronchiolitis obliterans (7). As the trend toward BLT for $\mathrm{PH}$ has continued in the early 2000s, Brouckaert and colleagues conducted a large singe-center retrospective study comparing BLT to HLT over 24 years (8). In the absence of a prospective, randomized trial, this work found no significant difference in early mortality and overall graft survival between the two transplant options. Therefore, consensus statements since the 2010s support BLTs as the preferred surgical treatment in $\mathrm{PH}$ (9).

\section{Pre-transplant management}

Pulmonary arterial hypertension (PAH) is a complex disease with heterogeneous etiologies and varying clinical course $(10,11)$. The unique needs of this patient population necessitate a high quality, specialized, multi-disciplinary approach to diagnosis and management (12). Patients require close monitoring for progression of symptoms and response to therapies. Following the initial diagnosis of PAH, referral to an expert center is imperative (10). Appropriate classification of disease directly affects patient care, as clinical management of differing etiologies may differ greatly. The importance of properly diagnosing the etiology of a patient's $\mathrm{PH}$ is underscored by remarkable incongruences in care provided across centers. One program found that of 140 patients referred to their center, 72 patients $(51 \%)$ had a change in diagnosis following appropriate evaluation. Of 42 patients in this group started on therapy for $\mathrm{PH}$ prior to referral, 23 (57\%) patients were found to be on inappropriate medications (13). Risk stratification using validated criteria guides initial therapies and defines risk for mortality $(12,14,15)$. Patient's clinical and hemodynamic response to initial therapy has crucial prognostic value $(16,17)$. Of 383 patients with group $1 \mathrm{PH}$, those who remained in or improved to a low risk profile at one year had better survival at 1, 3 and 5 years than those remaining in, or worsening to an intermediate or high-risk profile (18).

Upfront multidrug therapy has become the standard of care for patients with significant disease (19-22). Patients with severe hemodynamic compromise may need to be initiated on parenteral therapies urgently. As hemodynamics worsen and the right heart fails, patients may suffer from profound volume overload, hepatic congestion, cardiac cachexia and renal failure, among other co-morbidities (23). Referral for lung transplantation is indicated in patients 
with progressive disease despite maximal appropriate medical therapy, and for those patients requiring parenteral therapy. Additionally, patients with phenotypes known to respond poorly to medical therapy, such as pulmonary venoocclusive disease (PVOD), should be referred promptly (9). Ideally, early referral allows time for patients to consider transplantation, and for the transplant teams to fully evaluate patient candidacy, while working to mitigate any potential risks (24).

Consideration of transplant listing should be made when a patient demonstrates high risk of short-term mortality, despite optimized medical therapy. Validated risk stratification tools $(14,15)$ bring objectivity to this decision. Patients stratified as high risk have a one-year mortality risk well in excess of $10 \%$. Since the 1-year mortality following lung transplantation is approximately $10 \%$ (5) there is a mortality benefit to offering transplantation in this highrisk cohort. Time on the waitlist is influenced by many factors, including the patient's lung allocation score (LAS), history of sensitization, blood group and size. Patients with $\mathrm{PH}$ on the lung transplant wait listing have higher rates of mortality than peers without PH $(25,26)$ and it has been observed that the LAS disadvantages patients with PH (27). Revisions to the LAS have sought to appropriately capture illness severity, though in some countries, an exception score may be requested from a local review board when the transplant team feels that the calculated LAS does not adequately reflect the severity of patient illness.

Patients with $\mathrm{PH}$ and decompensated right heart failure are at high risk for mortality and should be managed at expert centers by experienced teams capable of providing high quality intensive care. Teams should have the ability to implement invasive therapies including extracorporeal support devices when the clinical situation remains dire despite maximal medical therapy. Goals of such interventions are to decompress the overloaded right heart, decrease flow and resistance through the pulmonary circulation, and provide adequately oxygenated blood to the systemic circulation. Prior to implementing such a strategy, it is imperative to clearly delineate goals of therapy, whether they are palliative in nature, as a bridge to recovery or a bridge to transplantation.

Atrial septostomy allows right to left shunting of deoxygenated blood. Though arterial desaturation is expected, this procedure augments cardiac output and increases overall systemic delivery of oxygen. In specialized centers, a more likely approach would be the use of extracorporeal life support (ECLS) devices. Venoarterial
(VA) extracorporeal membrane oxygenation (ECMO) decompresses the right heart and pulmonary circulation via venous outflow cannulas. Blood is directed through a membrane oxygenator and subsequently pumped into the systemic circulation, where the now well-oxygenated blood perfuses tissue beds. Though less commonly utilized, venovenous (VV) configurations of ECMO may be considered in appropriate situations. This form of mechanical support withdraws vena caval blood, directs it through a membrane oxygenator, and then reintroduces this well oxygenated blood into the right sided circulation. The downside of VV ECMO (when isolated as pure ECMO) is that no right ventricular support is provided and the cardiac and pulmonary circulation is reliant on intrinsic cardiac function. Alternative to this pure VV ECMO approach is utilizing a single site, percutaneous cannula such as the ProtekDuo (LinaNova, Boston, MA) (28).

The pure VV ECMO configuration may be best employed in patients with atrial septal defects or a patent foramen ovale allowing direct instillation of oxygenated blood into the systemic circulation (29). In mechanically ventilated patients, VV-ECMO may allow for the use of ultra-protective ventilator settings, limiting applied pulmonary arterial pressures (30). A final form of extracorporeal oxygenation is performed by placement of a membrane oxygenator directly between the pulmonary artery and left atrium. In patients with $\mathrm{PH}$, blood can flow through this low resistance oxygenator driven by native high right sided pressures, simultaneously offloading the right sided circulation and providing oxygenated blood to the systemic circulation $(31,32)$.

Considerations when employing ECLS devices include anticipated time to transplantation, and complications related to ECLS devices, such as coagulopathy, cerebral vascular accidents, venous thrombosis, bleeding and infection (33). With increasing experience with ECLS, complication rates have decreased over time.

ECMO techniques have been increasingly deployed as a bridge to transplantation (31,34-37), and patients can be maintained on ECLS for long periods of time (35), though ongoing mobilization and conditioning are important when choosing vascular access sites. When choosing access sites, risks and benefits of central versus peripheral cannulation must be considered. Peripheral femoral cannulation techniques are easiest to deploy, but limit patient mobility. In bi-femoral VA-ECMO, it is important to consider the mixing point between the retrograde flow of oxygenated post membrane-oxygenator blood and the deoxygenated 
blood ejected antegrade from the left ventricle. Patients may have poorly oxygenated blood supplied to their coronary or cerebral vasculature and this must be closely monitored. Large caliber arterial femoral cannulas may obstruct antegrade flow to the distal limb, placing the limb at risk for ischemic complications. A distal perfusion cannula may be deployed if necessary. Central cannulation via sternotomy or thoracotomy obviates concerns related to limited mobility, limb ischemia and distal mixing points but requires an invasive implantation procedure. Peripheral cannulation with venous access via the superior vena cava, and arterial return via the ipsilateral subclavian artery allows for reinfusion of oxygenated blood directly into the proximal aortic arch, thus mitigating concerns regarding lower extremity ischemia and decreased mobility seen in bi-femoral access, while removing the need for central cannulation (38).

Subtypes of pulmonary arterial hypertension require special attention to management. Rapid progression of $\mathrm{PH}$ may occur in connective tissue diseases (CTD-PAH), especially systemic sclerosis (SSc), and requires close screening $(10,39)$. Immunosuppressive agents may lead to clinical improvement in some forms of CTD-PAH, though this has not been demonstrated in SSc-PAH (40). A higher mortality rate in CTD-PAH has been shown compared to idiopathic PAH. In one registry of $651 \mathrm{PAH}$ patients, despite less severe hemodynamics, the median survival for patients with SSc-PAH was 3 years, compared to 7.8 years seen in idiopathic PAH (41). One, three- and five-year post transplant mortality was lower in SSc patients with PAH compared to those with SSc related interstitial lung disease with or without $\mathrm{PH}$ (42).

Pulmonary venous obstructive disease is typically refractory to pulmonary vasodilators, which may induce pulmonary edema and precipitate rapid clinical worsening. Referral for lung transplantation should be made at the time of diagnosis, as PVOD is frequently rapidly progressive. An analysis of the United Network for Organ Sharing (UNOS) database showed that at 6 months, $22 \%$ of patients with PVOD had died on the lung transplant waiting list, compared to $11 \%$ with PAH, despite similar a similar LAS (43).

CTEPH is currently the only potentially curable form of PH. Pulmonary endarterectomy (PEA) may reverse a patient's hemodynamic derangements and offers an excellent long-term survival benefit, with ten-year survival in excess of $70 \%$ reported (44). In patients with CTEPH, PEA offers a $63 \%$ relative risk reduction of death compared to those who do not undergo PEA (45). In up to one-third of patients, those with distal disease or otherwise non-operable cases, pulmonary balloon angioplasty is a viable treatment option, durably lowering pulmonary vascular resistance and improving exercise capacity and offering excellent 5 -year survival rates of up to $98.4 \%$ (46).

\section{Transplantation}

As a patient's medical therapy has been optimized and they have undergone appropriate institutional transplant evaluation, the timing and choice of transplant become key branch points in the patient's care plan. There are limited true contraindications to lung transplant from a surgical perspective although a history of previous chest surgery, presence of conditions exacerbated by cardiopulmonary bypass $(\mathrm{CPB})$ (e.g., bleeding disorders, cerebrovascular disease, and renal disease), and age of patient at time of transplantation should be given special consideration. The technically challenging situation of reoperative thoracic surgery can adversely affect outcomes such as increased bleeding, nerve injury, renal insufficiency and respiratory complications (47). Choice of surgical incision may vary per surgeon and institutional preference from median sternotomy to a bilateral clamshell approach. In cases with prior chest surgery, alternative cannulation sites for ECLS and $\mathrm{CPB}$ should be considered regardless of the higher risk of limb ischemia and vein thrombosis (48).

Right heart function and ability to tolerate single lung ventilation must be considered in planning for circulatory support in BLTs, particularly in the patient with endstage $\mathrm{PH}$. Many surgeons continue to utilize CPB in the setting of high pulmonary pressures and in otherwise highrisk patient populations (49). Despite this, newer studies support the transition to ECLS as CPB has been identified as an independent risk factor for primary graft dysfunction (50-52). Asimakopoulos and colleagues showed worsening of pulmonary function and significant inflammatory response with the use of $\mathrm{CPB}$ culminating in acute lung injury and therefore favor ECLS when performing lung transplantation (53). A 2018 retrospective study compared central and peripheral ECMO in BLT and found long-term survival and in-hospital mortality were unaffected on the basis of cannulation sites (54).

As surgical planning is needed for optimal outcomes, anesthesia is a key player in the operating room's multidisciplinary approach. Airway management with bronchial blockers (BB) or double-lumen endotracheal tubes (DLTs) each offer differing advantages and disadvantages. 
In a 2015 meta-analysis in thoracic surgery cases, BBs were shown to have lower incidence of airway injury, though DLTs could be placed with higher reliability and speed (55). Induction of anesthesia in $\mathrm{PH}$ patient with right heart dysfunction is difficult to manage and the anesthesia team must combat the ill effects of systemic vasodilation and subsequent reduction in right ventricular preload (56). Pre-induction initiation, or preparation of peripheral ECLS cannulation sites can expedite initiation of circulatory support, thereby avoiding acute right heart failure.

Postoperative care of $\mathrm{PH}$ transplant patients poses a new set of challenges unlike those issues encountered in the operating room. As lung physiology normalizes with the immediate reduction of pulmonary vascular resistance, the left ventricular filling pressure and cardiac output increase and can unmask left sided dysfunction (57). A strategy of post-operative continuation of ECLS to allow controlled normalization of global cardiac hemodynamics has been shown to greatly decrease both the incidence of PGD and incidence of early (within 3 months) mortality (58). The prolonged ECLS approach has recently been expanded to prevention to primary graft dysfunction (59).

\section{Future}

Pulmonary arterial hypertension remains an incurable disease and will likely remain so for the foreseeable future, however remarkable progress has been made over the last two decades. An improved understanding of the pathophysiology of pulmonary arterial hypertension has helped to identify the prostaglandin, nitric oxide and endothelin pathways as important therapeutic targets. Ongoing research has led to an improved understanding of pathways underlying the cellular dysfunction leading to $\mathrm{PAH}$, opening new potential therapeutic and diagnostic avenues. Mutations in bone morphogenetic protein receptor type 2 (BMPR2) have been demonstrated in $80 \%$ of families with $\mathrm{PAH}$ and in $20 \%$ of idiopathic $\mathrm{PAH}$ cases (60). Elucidation of the signaling pathways and associated proteins has led to trials repurposing existing medications, as well as a number of potential new therapies, currently in various stages of clinical research (61). In experimental PAH models, perivascular infiltrates of inflammatory cells have been seen preceding structural vascular changes, leading to an immunity driven hypothesis of PAH, and the investigation of inflammatory modulators for this disease (62). Mutations in the recently discovered gene
EIF2AK4 can accurately diagnose the rare PAH variants PVOD and pulmonary capillary hemangiomatosis (PCH) without the need for tissue biopsy (61). An ever-expanding population of genes and mutant proteins has been found in familial and sporadic forms of $\mathrm{PH}$ and are ongoing topics of investigation $(11,61,62)$. In addition to new medications, emerging techniques such as nanoparticle delivery provide the opportunity to improve on the pharmacokinetic profiles of established therapies (63).

Advances in mechanical interventions for management of $\mathrm{PH}$ also hold great promise. Recently described success in prolonged post-lung transplant ECMO supportallowing for cardiac accommodation to a newly low resistance pulmonary circulation-mitigates primary graft dysfunction and decreases the high early mortality rates seen in this population $(33,35,58)$. If widely accepted, this practice may lead to great improvements in longterm mortality in patients with PAH. As the number of centers performing both pulmonary endarterectomy and pulmonary balloon angioplasty increases, patients with CTEPH will increasingly be able to avoid transplantation. Finally, new interventions are finding their way into clinical care. Pulmonary artery denervation has shown promise in improving hemodynamic parameters and six-minute walk distance in patients with $\mathrm{PAH}$ in patients with disease refractory to maximal medical therapy (64). If ongoing trials prove successful, clinicians will have a new tool in combatting this devastating disease $(65,66)$.

The disease process of pulmonary arterial hypertension is an exemplar of how basic science research and a fundamental understanding of physiology can directly affect clinical care and profoundly improve disease outcomes. This once uniformly fatal disease can now regularly be managed with oral therapies. When disease becomes severe, the expanding, and ever improving armamentarium of therapeutic interventions, including lung transplantation offers realistic hope for improved quality and quantity of life. PH remains an area of active research. As of this writing, well in excess of 200 studies evaluating diagnostic, new and existing pharmacologic agents and therapeutic modalities are currently enrolling PAH patients. The future of $\mathrm{PH}$ has never looked brighter.

\section{Acknowledgments}

Funding: None. 


\section{Footnote}

Provenance and Peer Review: This article was commissioned by the Guest Editor (Jonathan D'Cunha) for the series "Lung Transplantation: Past, Present, and Future" published in Fournal of Thoracic Disease. The article has undergone external peer review.

Conflicts of Interest: All authors have completed the ICMJE uniform disclosure form (available at https://dx.doi. org/10.21037/jtd-2021-20). The series "Lung Transplantation: Past, Present, and Future" was commissioned by the editorial office without any funding or sponsorship. BAW serves as an unpaid editorial board member of fournal of Thoracic Disease from August 2019 to July 2021. BAW is a consultant for Abbott Laboratories and serves on the Clinical Events Committee of TransMedics OCS. All authors have no other conflicts of interest to declare.

Ethical Statement: All authors are accountable for all aspects of the work in ensuring that questions related to the accuracy or integrity of any part of the work are appropriately investigated and resolved.

Open Access Statement: This is an Open Access article distributed in accordance with the Creative Commons Attribution-NonCommercial-NoDerivs 4.0 International License (CC BY-NC-ND 4.0), which permits the noncommercial replication and distribution of the article with the strict proviso that no changes or edits are made and the original work is properly cited (including links to both the formal publication through the relevant DOI and the license). See: https://creativecommons.org/licenses/by-nc-nd/4.0/.

\section{References}

1. Dresdale DT, Schultz M, Michtom RJ. Primary pulmonary hypertension. I. Clinical and hemodynamic study. Am J Med 1951;11:686-705.

2. Derom F, Barbier F, Ringoir S, et al. Ten-month survival after lung homotransplantation in man. J Thorac Cardiovasc Surg 1971;61:835-46.

3. Reitz BA. The first successful combined heartlung transplantation. J Thorac Cardiovasc Surg 2011;141:867-9.

4. Hardy JD, Webb WR, Dalton ML Jr, et al. Lung Homotransplantation in Man. JAMA 1963;186:1065-74.

5. Chambers DC, Cherikh WS, Harhay MO, et al. The
International Thoracic Organ Transplant Registry of the International Society for Heart and Lung Transplantation: Thirty-sixth adult lung and heart-lung transplantation Report-2019; Focus theme: Donor and recipient size match. J Heart Lung Transplant 2019;38:1042-55.

6. Lala A. Transplantation in end-stage pulmonary hypertension (Third International Right Heart Failure Summit, part 3). Pulm Circ 2014;4:717-27.

7. Davis RD Jr, Pasque MK. Pulmonary transplantation. Ann Surg 1995;221:14-28.

8. Brouckaert J, Verleden SE, Verbelen T, et al. Doublelung versus heart-lung transplantation for precapillary pulmonary arterial hypertension: a 24-year single-center retrospective study. Transpl Int 2019;32:717-29.

9. Weill D, Benden C, Corris PA, et al. A consensus document for the selection of lung transplant candidates: 2014--an update from the Pulmonary Transplantation Council of the International Society for Heart and Lung Transplantation. J Heart Lung Transplant 2015;34:1-15.

10. Frost A, Badesch D, Gibbs JSR, et al. Diagnosis of pulmonary hypertension. Eur Respir J 2019;53:1801904.

11. Simonneau G, Montani D, Celermajer DS, et al. Haemodynamic definitions and updated clinical classification of pulmonary hypertension. Eur Respir J 2019;53:1801913.

12. Lau EM, Tamura Y, McGoon MD, et al. The 2015 ESC/ERS Guidelines for the diagnosis and treatment of pulmonary hypertension: a practical chronicle of progress. Eur Respir J 2015;46:879-82.

13. Deaño RC, Glassner-Kolmin C, Rubenfire M, et al. Referral of patients with pulmonary hypertension diagnoses to tertiary pulmonary hypertension centers: the multicenter RePHerral study. JAMA Intern Med 2013;173:887-93.

14. Hoeper MM, Kramer T, Pan Z, et al. Mortality in pulmonary arterial hypertension: prediction by the 2015 European pulmonary hypertension guidelines risk stratification model. Eur Respir J 2017;50:1700740.

15. Benza RL, Gomberg-Maitland M, Elliott CG, et al. Predicting Survival in Patients With Pulmonary Arterial Hypertension: The REVEAL Risk Score Calculator 2.0 and Comparison With ESC/ERS-Based Risk Assessment Strategies. Chest 2019;156:323-37.

16. Boucly A, Weatherald J, Savale L, et al. Risk assessment, prognosis and guideline implementation in pulmonary arterial hypertension. Eur Respir J 2017;50:1700889.

17. Weatherald J, Boucly A, Sahay S, et al. The Low-Risk Profile in Pulmonary Arterial Hypertension. Time for a 
Paradigm Shift to Goal-oriented Clinical Trial Endpoints? Am J Respir Crit Care Med 2018;197:860-8.

18. Kylhammar D, Kjellstrom B, Hjalmarsson C, et al. A comprehensive risk stratification at early follow-up determines prognosis in pulmonary arterial hypertension. Eur Heart J 2018;39:4175-81.

19. Galiè N, Barbera JA, Frost AE, et al. Initial Use of Ambrisentan plus Tadalafil in Pulmonary Arterial Hypertension. N Engl J Med 2015;373:834-44.

20. Sitbon O, Jais X, Savale L, et al. Upfront triple combination therapy in pulmonary arterial hypertension: a pilot study. Eur Respir J 2014;43:1691-7.

21. Sitbon O, Sattler C, Bertoletti L, et al. Initial dual oral combination therapy in pulmonary arterial hypertension. Eur Respir J 2016;47:1727-36.

22. Frost AE, Hoeper MM, Barbera JA, et al. Risk-stratified outcomes with initial combination therapy in pulmonary arterial hypertension: Application of the REVEAL risk score. J Heart Lung Transplant 2018;37:1410-7.

23. Lang IM, Palazzini M. The burden of comorbidities in pulmonary arterial hypertension. Eur Heart J Suppl 2019;21:K21-K28.

24. Quezada-Loaiza CA, de Pablo Gafas A, Perez V, et al. Lung Transplantation in Pulmonary Hypertension: A Multidisciplinary Unit's Management Experience. Transplant Proc 2018;50:1496-503.

25. Schaffer JM, Singh SK, Joyce DL, et al. Transplantation for idiopathic pulmonary arterial hypertension: improvement in the lung allocation score era. Circulation 2013;127:2503-13.

26. Chen H, Shiboski SC, Golden JA, et al. Impact of the lung allocation score on lung transplantation for pulmonary arterial hypertension. Am J Respir Crit Care Med 2009;180:468-74.

27. Gomberg-Maitland M, Glassner-Kolmin C, Watson S, et al. Survival in pulmonary arterial hypertension patients awaiting lung transplantation. J Heart Lung Transplant 2013;32:1179-86.

28. Malik M, Kilic A, Whitson BA. Percutaneous Single-Site Cannulation for Acute Right-Sided Support. ASAIO J 2017;63:844-6.

29. Srivastava MC, Ramani GV, Garcia JP, et al. Venovenous extracorporeal membrane oxygenation bridging to pharmacotherapy in pulmonary arterial hypertensive crisis. J Heart Lung Transplant 2010;29:811-3.

30. Reis Miranda D, van Thiel R, Brodie D, et al. Right ventricular unloading after initiation of venovenous extracorporeal membrane oxygenation. Am J Respir Crit Care Med 2015;191:346-8.

31. de Perrot M, Granton JT, McRae K, et al. Impact of extracorporeal life support on outcome in patients with idiopathic pulmonary arterial hypertension awaiting lung transplantation. J Heart Lung Transplant 2011;30:997-1002.

32. Fischer S, Simon AR, Welte T, et al. Bridge to lung transplantation with the novel pumpless interventional lung assist device NovaLung. J Thorac Cardiovasc Surg 2006;131:719-23.

33. Moser B, Jaksch P, Taghavi S, et al. Lung transplantation for idiopathic pulmonary arterial hypertension on intraoperative and postoperatively prolonged extracorporeal membrane oxygenation provides optimally controlled reperfusion and excellent outcome. Eur J Cardiothorac Surg 2018;53:178-85.

34. Hayanga AJ, Aboagye J, Esper S, et al. Extracorporeal membrane oxygenation as a bridge to lung transplantation in the United States: an evolving strategy in the management of rapidly advancing pulmonary disease. J Thorac Cardiovasc Surg 2015;149:291-6.

35. Rosenzweig EB, Gannon WD, Madahar P, et al. Extracorporeal life support bridge for pulmonary hypertension: A high-volume single-center experience. J Heart Lung Transplant 2019;38:1275-85.

36. Sabashnikov A, Mohite PN, Zeriouh M, et al. The role of extracorporeal life support in the management with severe idiopathic pulmonary artery hypertension undergoing lung transplantation: are those patients referred too late? J Thorac Dis 2019;11:S929-S937.

37. Hoeper MM, Benza RL, Corris P, et al. Intensive care, right ventricular support and lung transplantation in patients with pulmonary hypertension. Eur Respir J 2019;53:1801906.

38. Abrams DC, Brodie D, Rosenzweig EB, et al. Upperbody extracorporeal membrane oxygenation as a strategy in decompensated pulmonary arterial hypertension. Pulm Circ 2013;3:432-5.

39. Young A, Nagaraja V, Basilious M, et al. Update of screening and diagnostic modalities for connective tissue disease-associated pulmonary arterial hypertension. Semin Arthritis Rheum 2019;48:1059-67.

40. Aithala R, Alex AG, Danda D. Pulmonary hypertension in connective tissue diseases: an update. Int J Rheum Dis 2017;20:5-24.

41. Ramjug S, Hussain N, Hurdman J, et al. Idiopathic 
and Systemic Sclerosis-Associated Pulmonary Arterial Hypertension: A Comparison of Demographic, Hemodynamic, and MRI Characteristics and Outcomes. Chest 2017;152:92-102.

42. Pradère $P$, Tudorache I, Magnusson $\mathrm{J}$, et al. Lung transplantation for scleroderma lung disease: An international, multicenter, observational cohort study. J Heart Lung Transplant 2018;37:903-11.

43. Wille KM, Sharma NS, Kulkarni T, et al. Characteristics of patients with pulmonary venoocclusive disease awaiting transplantation. Ann Am Thorac Soc 2014;11:1411-8.

44. Jenkins D, Madani M, Fadel E, et al. Pulmonary endarterectomy in the management of chronic thromboembolic pulmonary hypertension. Eur Respir Rev 2017;26:160111.

45. Delcroix M, Lang I, Pepke-Zaba J, et al. Long-Term Outcome of Patients With Chronic Thromboembolic Pulmonary Hypertension: Results From an International Prospective Registry. Circulation 2016;133:859-71.

46. Aoki T, Sugimura K, Tatebe S, et al. Comprehensive evaluation of the effectiveness and safety of balloon pulmonary angioplasty for inoperable chronic thromboembolic pulmonary hypertension: long-term effects and procedure-related complications. Eur Heart J 2017;38:3152-9.

47. Shigemura N, Bhama J, Gries CJ, et al. Lung transplantation in patients with prior cardiothoracic surgical procedures. Am J Transplant 2012;12:1249-55.

48. Pavlushkov E, Berman M, Valchanov K. Cannulation techniques for extracorporeal life support. Ann Transl Med 2017;5:70.

49. Bittner HB, Binner C, Lehmann S, et al. Replacing cardiopulmonary bypass with extracorporeal membrane oxygenation in lung transplantation operations. Eur J Cardiothorac Surg 2007;31:462-7; discussion 467.

50. Ius F, Kuehn C, Tudorache I, et al. Lung transplantation on cardiopulmonary support: venoarterial extracorporeal membrane oxygenation outperformed cardiopulmonary bypass. J Thorac Cardiovasc Surg 2012;144:1510-6.

51. Diamond JM, Lee JC, Kawut SM, et al. Clinical risk factors for primary graft dysfunction after lung transplantation. Am J Respir Crit Care Med 2013;187:527-34.

52. Aigner $\mathrm{C}, \mathrm{Wisser} \mathrm{W}$, Taghavi $\mathrm{S}$, et al. Institutional experience with extracorporeal membrane oxygenation in lung transplantation. Eur J Cardiothorac Surg
2007;31:468-73; discussion 473-4.

53. Asimakopoulos G, Smith PL, Ratnatunga CP, et al. Lung injury and acute respiratory distress syndrome after cardiopulmonary bypass. Ann Thorac Surg 1999;68:1107-15.

54. Glorion M, Mercier O, Mitilian D, et al. Central versus peripheral cannulation of extracorporeal membrane oxygenation support during double lung transplant for pulmonary hypertension. Eur J Cardiothorac Surg 2018;54:341-7.

55. Clayton-Smith A, Bennett K, Alston RP, et al. A Comparison of the Efficacy and Adverse Effects of Double-Lumen Endobronchial Tubes and Bronchial Blockers in Thoracic Surgery: A Systematic Review and Meta-analysis of Randomized Controlled Trials. J Cardiothorac Vasc Anesth 2015;29:955-66.

56. Kachulis B, Mitrev L, Jordan D. Intraoperative anesthetic management of lung transplantation patients. Best Pract Res Clin Anaesthesiol 2017;31:261-72.

57. Bîrsan T, Kranz A, Mares P, et al. Transient left ventricular failure following bilateral lung transplantation for pulmonary hypertension. J Heart Lung Transplant 1999; 18:304-9.

58. Tudorache I, Sommer W, Kuhn C, et al. Lung transplantation for severe pulmonary hypertension-awake extracorporeal membrane oxygenation for postoperative left ventricular remodelling. Transplantation 2015;99:451-8.

59. Hoetzenecker K, Schwarz S, Muckenhuber M, et al. Intraoperative extracorporeal membrane oxygenation and the possibility of postoperative prolongation improve survival in bilateral lung transplantation. J Thorac Cardiovasc Surg 2018;155:2193-206.e3.

60. Evans JD, Girerd B, Montani D, et al. BMPR2 mutations and survival in pulmonary arterial hypertension: an individual participant data meta-analysis. Lancet Respir Med 2016;4:129-37.

61. Morrell NW, Aldred MA, Chung WK, et al. Genetics and genomics of pulmonary arterial hypertension. Eur Respir J 2019;53:1801899.

62. Humbert M, Guignabert C, Bonnet S, et al. Pathology and pathobiology of pulmonary hypertension: state of the art and research perspectives. Eur Respir J 2019;53:1801887.

63. Segura-Ibarra V, Wu S, Hassan N, et al. Nanotherapeutics for Treatment of Pulmonary Arterial Hypertension. Front Physiol 2018;9:890.

64. Zhang H, Chen SL. Pulmonary Artery Denervation: 
Update on Clinical Studies. Curr Cardiol Rep 2019;21:124.

65. Safety and efficacy of pulmonary artery denervation in patients with pulmonary arterial hypertension. Available online: https://ClinicalTrials.gov/show/NCT03282266

Cite this article as: Hwalek A, Rosenheck JP, Whitson BA. Lung transplantation for pulmonary hypertension. J Thorac Dis 2021;13(11):6708-6716. doi: 10.21037/jtd-2021-20
66. A Study to Investigate the Efficacy of PADN to Improved Functional Capacity and Hemodynamics in Patients With PAH. Available online: https://ClinicalTrials.gov/show/ NCT02284737 